\title{
The epidemiology of pain: the more you have, the more you get
}

Behind the dazzle of the search for diagnosis and cause, the fundamental concern of rheumatologists and their patients is pain. In frequency musculoskeletal pain ranks second only to respiratory conditions in the list of symptoms presented to general practitioners. ${ }^{1}$ Yet we are more content with the study of distinct clinicopathological syndromes than of pain per se. On an $x$ ray of the hip joints, for example, we fondly imagine that the changes we see-joint space narrowing, subchondral density, osteophytesreflect the state of underlying pathology: cartilage destruction, sclerosis, new bone formation. Even if we are unclear about the sequence of events, this picture means osteoarthritis. Yet in population surveys only about half of those with such definite radiographic changes report pain or stiffness in the joint. ${ }^{2}$ The same story emerges at other sites in the body: low back pain is not the same entity as spinal disease, for example, and cervical spondylosis does not explain most neck pain. Radiographic osteoarthritis or the aetiology of bony changes in the spine are legitimate objects of epidemiological study, but the investigation of the occurrence, the causes, and the management of musculoskeletal pain itself must be seen as a separate matter.

Population studies of pain, by the very nature of the subject, have to focus on what the people say rather than what the test shows. Standardisation of such information is helped by clear definitions of the part of the body with which the questions are concerned and the period of time of symptom recall. ${ }^{3}$ Our memories of pain are not perfect. A traditional question in surveys was, for example: "Have you ever suffered from low back pain?". The intriguing finding from this was that by the age of 30 years, almost $50 \%$ of adults in England and Wales recall low back pain that has lasted for longer than one day at least. ${ }^{45}$ This figure climbs to $60 \%$ by the age of 60 , but paradoxically falls after 70: a logical impossibility unless people who suffer from low back pain die earlier than other people or the elderly have a different low back pain experience from those born a decade or two later. More likely is that recall becomes blurred, and that the experience of low back pain is indeed already widespread by the time of young adulthood.

The consistent message from studies of low back and soft tissue pain is that the strongest risk for developing new symptoms is the fact of having had a previous episode. ${ }^{6}$ Such pain appears to track through an individual's life, each episode increasing the probability of having another one. This argues against the traditional separation of pain sufferers into the many who have acute short lived episodes and the few who develop long term chronic problems. Musculoskeletal pain in any one individual is conceptually a chronic problem, ${ }^{7}$ the pattern of which may include long periods of freedom from pain but which always contains the possibility of exacerbation or recurrence. It represents a spectrum, at one end of which are people who are in continual pain from day to day. This life history of pain in any one person is the outcome of a continuing and changing interplay between predisposition and environment. Any attempt to explain in simple fashion that occupational activity, for example, is a risk factor for low back pain is bedevilled by the fact that earlier pain experience might well have dictated the type of work that people do or their attitude towards their job.

The further we look into the way in which pain affects people throughout their lives, the more complex the picture becomes. In an interesting study from Norway, early pain experience was charted in a cohort of children. ${ }^{8}$ The commonest pain complaint at the age of 5 years was abdominal pain, but by 10 years headache dominated. Those children who complained of abdominal pain at the age of 5 were more likely than other children to be complaining of headache at the age of 10 . This raises intriguing questions about the pain experience of parents or close members of the family, the inheritance of pain, the culture of pain expression, and the possibility that the pattern of presentation of symptoms to the health care services is set from an early age.

It relates also to another important feature of musculoskeletal syndromes-their propensity to occur together. This concurrence is reported consistently across studies from different sources, examples including neck and low back pain, and upper limb and lower limb syndromes. ${ }^{9}$ The more areas of pain which are involved at any one time, the more likely that unaffected areas will become involved later. ${ }^{10}$ There are a number of potential explanations of this. Multiple joint involvement in osteoarthritis for example may reflect the strong age related incidence of the condition at all sites: older people are increasingly likely to develop problems at more than one site. ${ }^{11}$ It may reflect common pathogenesis: long years of heavy lifting is implicated in the aetiology of both hip and knee osteoarthritis, as well as low back pain and shoulder syndromes. ${ }^{1213}$ Other links-such as the influence of psychosocial factors on symptom occurrence-seem not to be specific to any one syndrome but a feature of persistent musculoskeletal pain in general. ${ }^{14}$ The pattern seems to be 
that local factors (mechanical stress and injury) may determine the initial location, but the reasons for persistence and recurrence are more general. Fibromyalgia represents the extreme example of this where the peripheral origins of the pain have become lost in the widespread nature of the problem.

The neuroscientists have provided theory and experiment to support the idea that pain expression is not simply a result of unhealed peripheral injury. Although warning against swinging the pendulum too far in the direction of all persistent pain being a creation of central mechanisms, Wall and others have contributed to the breakdown of the Cartesian separation of mind and body. ${ }^{15}$ Previous editorial writers on this topic have pointed to the way in which fibromyalgia fits the new model of what in Wall's words is a virtual reality world, in which central influences of emotion and cognition join with the consequences of peripheral injury to give painful symptoms a life of their own.

How much chronic musculoskeletal pain is related to such central influences, as summed up in the term "somatisation"? The core notion of somatisation is that psychological distress can be expressed as physical symptoms. To this the psychiatric epidemiologist would add the characteristic that those symptoms are presented to the health services. ${ }^{16}$ Only a minority of musculoskeletal pain is presented to the health care services at any one time. ${ }^{1}$ Musculoskeletal problems are the main reason for seeking complementary treatments in America and Europe,${ }^{17}$ which suggests that people in pain find routes to health care even if they are not the official ones. Even in general population studies, however, there is a consistent relation between measures of psychological distress and the extent of pain complaints. In an American population based study for example a strong association was found between major depression and the number of reported pain complaints. ${ }^{18}$

This last study, like so many surveys of low back and soft tissue pain in the population, was cross sectional, with the inevitable problem of disentangling cause and effect. It is as probable that chronic or persistent or widespread pain gives rise to anxiety and depression and psychological distress as it is to suppose that the causal link is the other way around. In studies carried out among Boeing workers in America, in a population based cohort from a Manchester population, and among factory workers in Finland, measures of distress at baseline predicted the likelihood of later episodes of low back or other musculoskeletal pain. ${ }^{19-21}$ There is a growing body of evidence that levels of distress in people presenting with low back pain in primary care or in the osteopath's surgery are the strongest predictors of outcome of the episode. ${ }^{22-24}$ These were all short term studies, and prior experience of pain might have influenced the way in which psychosocial distress became embedded in a painful context. We need to know whether such relations persist over a long period of time, and whether they represent longer term risks for persistent pain. There must still be a suspicion that the link between pain and psychological distress can never neatly be packaged into a linear process of cause and effect, and that childhood experiences, for example, or parental experiences, colour these relationships from an early age.
Why have rheumatologists avoided musculoskeletal pain? They should be the pain specialists and yet other clinicians and therapists dominate the field. Is it frustration at so many syndromes so difficult to pin down, most not attributable to obvious pathology, and no helpful clinical classifications to hand? The evidence from epidemiology suggests that pain and its persistence needs to be released from the straitjacket of our obsession with localisation and peripheral mechanisms, and studied as a phenomenon in its own right.

My work has been part of the team programmes at the Arthritis and Rheumatism Council's Epidemiology Unit in Manchester and the Medical Research Council's Environmental Epidemiology Unit in Southampton.

University of Keele, School of

Postgraduate Medicine, Hartshill,

Stoke-on-Trent ST4 7QB

1 McCormick A, Fleming D, Charlton J. Morbidity statistics from general practice. Fourth national study 1991-1992. Office of Population Censuses and Surveys. Series MB5 No 3. London: HMSO, 1995.

2 National Center for Health Statistics. Basic data on arthritis of the knee, hip and sacrioliac joints in adults aged 25-74 years. Washington, DC: US GPO, 1979. (Series 11, No 213.) DHEW publication No (PHS) 79-1161.

3 Raspe H. Back pain. In Silman AJ, Hochberg MC, eds. Epidemiology of the rheumatic diseases. Oxford: Oxford University Press, 1993.

4 Walsh $\mathrm{K}$, Cruddas $M$, Coggon D. Low back pain in eight areas of Britain. $f$ Epidemiol Community Health 1992;46:227-30.

5 Papageorgiou A, Croft P, Ferry S, Jayson MIV, Silman A. Estimating the prevalence of low back pain in the general population. Evidence from the South Manchester Back Pain Survey. Spine 1995;20:1889-94.

6 Roland MO, Morrell DC, Morris RW. Can general practitioners predict the outcome of episodes of back pain? $B M \mathcal{F} 1983 ; 286: 523-5$.

7 Deyo RA. Practice variations, treatment fads, rising disability. Spine 1993;18:2153-62.

8 Borge AIH, Nordhagen R, Moe B, Botten G, Bakketeig LS. Prevalence and persistence of stomach ache and headache among children. Follow-up of a cohort of Norwegian children. Acta Paediatr 1994;83:433-7.

9 Makela M. Common musculoskeletal syndromes. Helsinki: Social Insurance Institution, 1993.

10 Papageorgiou AC, Croft PR, Thomas E, Ferry S, Jayson MIV, Silman AJ Influence of previous pain experience on the episode incidence of low back pain. Pain 1996;66:181-5.

11 Kellgren JH, Lawrence JS. Osteoarthritis and disk degeneration in an urban population. Ann Rheum Dis 1958;17:388-97.

12 Vingard E, Alfredsson L, Goldie I, Hogstedt C. Occupation and osteoarthritis of the hip and knee: a register-based cohort study. Int $\mathcal{F}$ Epidemiol 1991;20:1025-31.

13 Walsh $\mathrm{K}$, Cruddas $M$, Coggon D. Interaction of height and mechanical loading of the spine in the development of low back pain. Scand $\mathcal{F}$ Work Environ Health 1991;17:420-4.

14 Magni G, Caldieron C, Rigatti-Luchini S, Merskey H. Chronic musculoskeletal pain and depressive symptoms in the general population. An analysis of the 1st National Health and Nutrition Examination Survey analysis of the 1st National
data. Pain 1990;43:299-307.

15 Wall PD. Introduction to Melzack R, Wall PD, eds. Textbook of pain, 3rd ed. Edinburgh: Churchill Livingstone, 1994.

16 Craig TKJ, Boardman AP, Mills K, Daly-Jones O, Drake H. The South London Somatisation Study. I: Longitudinal course and the influence of early life experiences. Br $\mathcal{F}$ Psychiatry 1993;163:579-88.

17 Eisenberg DM, Kessler RC, Foster C, Norlock FE, Calkins DR, Delbanco DL. Unconventional medicine in the United States. $N$ Engl f Med 1993;328:246-52.

18 Dworkin SF, Von Korff M, LeResche L. Multiple pains and psychiatric disturbance. Arch Gen Psychiatry 1990;47:239-44.

19 Bigos SJ, Battié MC, Spengler DM, Fisher LD, Fordyce WE, Hansson TH, et al. A prospective study of work perceptions and psychosocial factors affecting the report of back injury. Spine 1991;16:2-6.

20 Croft PR, Papageorgiou AC, Ferry S, Thomas E, Jayson MIV, Silman AJ. Psychologic distress and low back pain. Evidence from a prospective study in the general population. Spine 1996;20:2731-7.

21 Leino PI, Hanninen V. Psychosocial factors at work in relation to back and limb disorders. Scand $\mathcal{F}$ Work Environ Health 1995;21:134-42.

22 Main CJ, Wood PLR, Hollis S, Spanswick CC, Waddell G. The distress risk and assessment method. Spine 1991;17:42-52.

23 Klenerman L, Slade PD, Stanley IM, Pennie B, Reilly JP, Atchison LE, et al. The prediction of chronicity in patients with an acute attack of low back pain in a general practice setting. Spine 1995;20:478-84.

24 Von Korff M, Deyo RA, Cherkin D, Barlow W. Back pain in primary care: outcomes at 1 year. Spine 1993;18:855-62. 